\title{
Papers
}

\section{Consumer demand for caesarean sections in Brazil: informed decision making, patient choice, or social inequality? A population based birth cohort study linking ethnographic and epidemiological methods}

\author{
Dominique P Béhague, Cesar G Victora, Fernando C Barros
}

\begin{abstract}
Objectives To investigate why some women prefer caesarean sections and how decisions to medicalise birthing are influenced by patients, doctors, and the sociomedical environment.

Design Population based birth cohort study, using ethnographic and epidemiological methods. Setting Epidemiological study: women living in the urban area of Pelotas, Brazil who gave birth in hospital during the study. Ethnographic study: subsample of 80 women selected at random from the birth cohort. Nineteen medical staff were interviewed. Participants 5304 women who gave birth in any of the city's hospitals in 1993 .

Main outcome measures Birth by caesarean section or vaginal delivery.

Results In both samples women from families with higher incomes and higher levels of education had caesarean sections more often than other women. Many lower to middle class women sought caesarean sections to avoid what they considered poor quality care and medical neglect, resulting from social prejudice. These women used medicalised prenatal and birthing health care to increase their chance of acquiring a caesarean section, particularly if they had social power in the home. Both social power and women's behaviour towards seeking medicalised health care remained significantly associated with type of birth after controlling for family income and maternal education.

Conclusions Fear of substandard care is behind many poor women's preferences for a caesarean section. Variables pertaining to women's role in the process of redefining and negotiating medical risks were much stronger correlates of caesarean section rates than income or education. The unequal distribution of medical technology has altered concepts of good and normal birthing. Arguments supporting interventionist birthing for all on the basis of equal access to health care must be reviewed.
\end{abstract}

\section{Introduction}

Of 12 Latin American countries recently reviewed, Brazil had the second highest rate of caesarean sections ${ }^{1} ; 55 \%$ of women from families earning more than $\$ 1000$ (£700, €1120) per month had a caesarean section, above the $15 \%$ recommended by the World Health Organization. ${ }^{2}{ }^{3}$ Factors other than clinical indications play a major part in this inequitable distribution of caesarean sections.

Women's requests for caesarean section may be an important determinant of birth outcome, particularly in countries with growing privatisation and options for patient choice. ${ }^{4-8}$ Most research focuses on women's fears of the physiological consequences of vaginal delivery and their desire to keep their sexual performance intact. ${ }^{5}$ For this reason the debate has focused on providing consumers with knowledge on the risks associated with vaginal and operative deliveries so that decisions about birth may be rationally informed. ${ }^{10-14}$

Such approaches tell us little about how individual preferences for operative deliveries have grown from particular socioeconomic processes. How do women and obstetricians conclude that the risk of attempting a vaginal delivery is too high? ${ }^{13}{ }^{14}$ We investigated why some women seek out medicalised care. In particular, we explored how medicalisation is linked to social power in a society where the everyday experience of inequalities is profound.

\section{Methods}

We used a linked ethnographic and epidemiological approach for our study. For the ethnographic study we selected 80 mothers from a birth cohort of 5304 women who gave birth in 1993 in any of the hospitals in Pelotas, Brazil. ${ }^{2}$ We stratified these mothers by education and age, and we chose them at random until each quota was completed. We interviewed women two or three times during the first five months after birth, using a semistructured guide to explore women's health seeking behaviour, interactions with medical institutions, social integration and activities, and dynamics within the household.
Department of
Social Medicine,
Federal University
of Pelotas, CP
464-96001-970,
Pelotas, Rio Grande
do Sul, Brazil
Dominique P
Béhague
anthropologist
Cesar G Victora
professor of
epidemiology
Centro
Latinoamericano de
Perinatologia,
Montevideo,
Uruguay
Fernando C Barros
consultant
Correspondence to:
D P Béhague,
Department of
Anthropology,
McGill University,
Montreal, Quebec
H3A 2T7, Canada
dbehague@aol.com
bmj.com 2002;324:942 
We also interviewed 19 clinicians: six obstetricians, six paediatricians, four general practitioners, and three nurses. We taped and transcribed all interviews. Our analysis combined general overviews of thematic areas and a comparative approach. Gestational risk was measured with the score developed by Chamberlain and previously used in Pelotas. ${ }^{15}$

Qualitative research is based on the close observation of locally meaningful practices and their patterning. We created two scores by using simple dichotomous (yes or no) variables that, according to previous ethnographic understanding, were deemed to relate to a common underlying theme. These scores were not constructed in reference to an absolute gold standard but rather were used for their relative values as simple tools in the comparative analysis of women's experiences.

The maternal score for medicalisation is the sum of several variables: woman went to the hospital as soon as she felt any signs of labour, woman actively sought ultrasonography during the pregnancy, woman explicitly did not want to know what was going on during the birth, and woman stated she had expected a caesarean section or wanted one before entry to hospital. The score for socioeconomic power was based on several variables: woman stated she worked because she liked to have her own money, woman took part in decisions about the household, woman took money or goods without asking partner or family members, woman did not complain about how money was distributed in the home, woman acquired goods or services informally through exchange with others, and woman appeared more independent from partner or parents than other mothers in the sample. These two constructs represent underlying empirical issues that are important in several societies. ${ }^{16-18}$

\section{Results}

In Pelotas over $99 \%$ of births occur in hospital, most of which are dealt with by an obstetrician. ${ }^{19}$ No significant differences were found between the epidemiological and the ethnographic samples. In the epidemiological sample, $17 \%$ (923) of the mothers were under 20, 19\% (984) had a family income under $\$ 100$ (£70) a month, $28 \%$ (1492) had had less than five years of schooling, $35 \%$ (1860) were primiparous women, and 19\% (639) of those with one or more previous deliveries had had a caesarean section. Around 30\% (1619) of births were by caesarean sections and 32\% (1695) were induced.

Results from the epidemiological study are similar to those from the ethnographic subsample (table 1). Caesarean sections were more common among wealthy and educated women, those with more antenatal attendance, primiparous women and, paradoxically, those with a lower gestational risk. Overall, $83 \%$ of women who had had a caesarean section had repeat procedures. Apart from primiparous women, those with the greatest need for caesarean sections were the least likely to receive one. The ethnographic study investigated how this socioeconomic reality was experienced by both physicians and women.

Physicians noticed an increase in their patients' awareness of medical knowledge and the possibility of legal action, previously only found among patients from higher social classes. For some, this led to a loss of
Table 1 Frequency of caesarean sections according to family and maternal characteristics in 5304 women in Pelotas, 1993

\begin{tabular}{|c|c|}
\hline Characteristic & $\%$ (No) of caesarean sections \\
\hline \multicolumn{2}{|c|}{ Family income (minimum salaries) ${ }^{\star}$} \\
\hline$\leqslant 1$ & $23.5(231 / 984)$ \\
\hline $1.1-3$ & $25.1(572 / 2279)$ \\
\hline $3.1-6$ & $33.3(406 / 1218)$ \\
\hline$>6$ & $50.0(411 / 823)$ \\
\hline $\mathrm{P}$ value $\dagger$ & $<0.001$ \\
\hline \multicolumn{2}{|l|}{ Maternal schooling (years) } \\
\hline $0-4$ & $22.4(334 / 1492)$ \\
\hline 5-8 & $27.5(672 / 2448)$ \\
\hline$\geqslant 9$ & $45.0(614 / 1364)$ \\
\hline$P$ valuet & $<0.001$ \\
\hline \multicolumn{2}{|l|}{ No of antenatal visits } \\
\hline $0-4$ & $16.6(157 / 943)$ \\
\hline 5-9 & $28.0(797 / 2852)$ \\
\hline $10-20$ & $44.3(663 / 1497)$ \\
\hline $\mathrm{P}$ value $\dagger$ & $<0.001$ \\
\hline \multicolumn{2}{|l|}{ Parity } \\
\hline Primiparous & $34.0(631 / 1860)$ \\
\hline Multiparous & $28.7(989 / 3444)$ \\
\hline$P$ value $\dagger$ & $<0.001$ \\
\hline \multicolumn{2}{|l|}{ Birth history } \\
\hline Previous normal birth & $14.0(354 / 2538)$ \\
\hline Previous caesarean section & $83.3(532 / 639)$ \\
\hline $\mathrm{P}$ value $\dagger$ & $<0.001$ \\
\hline \multicolumn{2}{|l|}{ Gestational risk } \\
\hline Low (0-2) & $36.4(500 / 1372)$ \\
\hline Medium (3-7) & $28.8(949 / 3294)$ \\
\hline High $(\geqslant 8)$ & $26.8(171 / 637)$ \\
\hline $\mathrm{P}$ value $\dagger$ & $<0.001$ \\
\hline \multicolumn{2}{|l|}{ Induction } \\
\hline No & $37.6(1358 / 3609)$ \\
\hline Yes & $15.5(262 / 1695)$ \\
\hline $\mathrm{P}$ value $\dagger$ & $<0.001$ \\
\hline \multicolumn{2}{|l|}{ Maternal powert } \\
\hline Less $(0-1)$ & $10.6(5 / 47)$ \\
\hline More $(\geqslant 2)$ & $51.6(16 / 31)$ \\
\hline$P$ valuet & $<0.001$ \\
\hline \multicolumn{2}{|c|}{ Medicalised approach towards birthł } \\
\hline Less $(0-2)$ & $14.0(7 / 50)$ \\
\hline More $(\geq 3)$ & $46.7(14 / 30)$ \\
\hline $\bar{P}$ value† & 0.001 \\
\hline
\end{tabular}

${ }^{*}$ One minimum salary $=\$ 100(£ 70)$.

$+\chi^{2}$ test for heterogeneity.

$\ddagger$ Primiparous women excluded.

§Information available only for mothers in ethnographic sample.

control over patients (box). Before arriving at the hospital 32 women (40\%) from the ethnographic study said they expected to have a caesarean section. A vaginal birth was considered a risky and negative experience, whereas caesarean sections represented the best quality care. When asked why women preferred caesarean sections, almost all recounted problems with fetal distress and mortality, excessive pain, or trauma to the vagina (see box).

According to some women, a traumatic vaginal birth often occurred because of medical negligence based on social and economic prejudice. Some explained that poor or uneducated women, teenage mothers, women with few antenatal attendances, those with "too many" children, and women who were believed to not want their child were least likely to receive any kind of medical attention, including interventions. These women were said to have to plead for induction by "making a scandal" during the birth to attract medical attention. For medical staff, however, 


\section{Excerpts from ethnographic interviews}

\section{Obstetricians}

Mario

Mario: Women now have more knowledge, and they make more demands. Today, for example, when a patient

becomes pregnant she will, without a doubt, want that baby. In the past, if she lost it, it was just another death. Today, it's always the physician's mistake.

Interviewer: But some things are surely out of the physician's control?

Mario: This is true, but if we had better antenatal technology, for example, things would work better.

João

João: There's a lot of propaganda from the First World. People see the technology that the First World has, and since they pay taxes, they think they should have the right to demand highly sophisticated exams. They don't realise that these things are not in the hands of the doctors. There's a multinational insurance company that owns a portion of one of the television stations, so they manipulate the media. This is the sort of thing that makes people want a kind of medicine that just isn't available.

Silvio

Interviewer: What is it like in your private practice?

Silvio: Here it's a pleasure to attend people, but in the public sector, you don't always know the patient, they don't always know you, you don't have a history with them ... they don't have any confidence in you. For example, it's harder to convince the families in the public sector that it's normal for a woman to be in labour for 8 hours, they don't believe you.

\section{Women}

Jocilda

Jocilda: I should have had a c-section. I was about to faint. I lost my strength. The baby was stuck-they should have taken him out to avoid his suffering. These are justified emergency c-sections; when the baby is suffering. In my case, the doctors did everything to avoid a c-section. I am absolutely certain that they made a point of not doing a c-section on me and insisting in a normal birth. They kept saying that a normal birth would be better for the baby ... but in the end, it was not possible.

Interviewer: And who tends to get a c-section in general?

Jocilda: People who don't want to feel pain ... but pain is normal ... I also think people with money do c-sections. I've seen many cases of women that go to the hospital with money, and the doctors say, "listen, we may very well do a c-section."

\section{Maria}

Maria: They only do a c-section if the person is dying, you rip all over down there, and there's nothing to be done. They'll even use forceps if they have to, to avoid doing a caesarean section. This happened to my sister in law; they took her baby out with forceps, poor thing, both of them ... it's much worse when the child gets stuck.

Neighbour: Can you imagine? Stick metal in there to pull the child out, the pain that one must feel? It's a horror ... now you know, for your birth, you pay for it.

Maria: Yes, start saving now, put some money away so you can do your caesarean.

Neighbour: Yes, all you have to do is say you want a caesarean, that you don't want to suffer, pay and it's done. Interviewer: Why do you think they didn't do a caesarean in your case?

Maria: The doctor felt nauseous when he looked at me because I didn't do antenatal care, they don't like people who don't do antenatal care.

\section{Aline}

Aline: All was fine with me since I work at the hospital as an attendant and the doctors know me. That's why they did not do any stupidities like they often do with other people, with the poor vagabonds.

Interviewer: You were lucky then.

Aline: No! It wasn't luck, not at all. Doctors need us, because they aren't the ones that take care of the medications. Attendants are the ones to do that. They need us, and we need them. They know that they can't treat us poorly. My doctor, the one that I did my prenatal care with, told me to show up during his night shift-that way, he would do the caesarean.

\section{Elza}

Interviewer: Did it ever cross your mind that it may be a caesarean section before the birth?

Elza: Yes, because of the baby's size. She was a fat little baby, very healthy ... I thought about it during the birth too ... I thought, better to just cut soon. I was really scared. I thought this would be better.

Interviewer: What did the people at the hospital say?

Elza: The doctor asked me when I got there if I was used to doing c-sections. I told him no, that I had only had normal births.

\section{Andrezza}

Andrezza: I thought I was going to die. My mother kept trying to tell the doctor I was really feeling bad. He said it was supposed to be like that. Then I said, "I can't take it any more!" Then the doctor said, "You made a child and you didn't know it was going to hurt so much!" So I told him, "You know doctor, you are a really stupid man, because this is my first child; how am I supposed to know." So he said, "Well, then before doing it (having sex), you should have found out from others!" I told him, "Oh, Mr doctor, you don't have the guts that I do!" Then I tried kicking him, but the lady doctor told me to calm down, to not act like that, because otherwise they would mistreat me once inside, during the caesarean section.

\section{Eva}

Eva: I didn't have any symptoms, none at all, but I would go to the hospital every day or so, because of my problem. One day I went, I arrived at 740 and by 9 o'clock they did the caesarean. In one hour and 20 minutes, she was born. It was something incredible, really quick, very impressive care. I think even if it had been a private caesarean, it would not have been so quick and gone so well. 
Table 2 Pearson's correlation for ethnographic sample of 80 women

\begin{tabular}{|c|c|c|c|}
\hline Characteristic & $\begin{array}{l}\text { Maternal } \\
\text { schooling }\end{array}$ & $\begin{array}{l}\text { Medicalised } \\
\text { approach to birth }\end{array}$ & $\begin{array}{l}\text { Maternal power in } \\
\text { home }\end{array}$ \\
\hline Family income $(\mathrm{n}=77)$ & $0.475^{\star \star \star}$ & $0.252^{*}$ & $0.499^{\star \star \star}$ \\
\hline Maternal schooling & & $0.239^{*}$ & $0.344^{* *}$ \\
\hline Medicalised approach to birth & & & $0.269^{*}$ \\
\hline
\end{tabular}

women's "excessive" screaming indicated a lack of psychological preparation for birth and even desire for the child.

Attempts to avoid a vaginal birth were partly due to antagonistic relationships with medical staff. Women who did not have the money to pay for a caesarean section resorted to indirect methods, such as going to the hospital early in labour to pressure the on-call obstetrician for interventions, seeking an obstetrician who was known to perform caesarean sections (paying for the occasional private consultation), attending hospital outpatient care rather than local facilities to increase the chances of getting to know obstetricians (despite increased costs due to transportation), requesting ultrasonography, despite it being indicated only in high risk pregnancies in women in the public sector, and paying the on-call obstetrician half price for a caesarean section.

\section{Affect of women's healthcare seeking behaviour on birth outcome}

The relation between women's healthcare seeking behaviour and birth outcome were explored statistically for the ethnographic subsample of 80 women. Women with a more medicalised approach towards birthing had more caesarean sections (table 1). Despite economic constraints, women with more decision making power in the home were more able to implement such medicalised behaviours. These women tended to allocate resources for medicalised care (antenatal and birth), particularly if they feared lack of proper medical treatment during delivery. Women with more socioeconomic power in the home also tended to have a caesarean section (table 1).

Power for decision making in the home and seeking medicalised health care were associated with higher maternal education and family incomes (table 2). The effects of maternal education on uptake of caesarean section disappeared when power for decision making and medicalisation were taken into account (table 3). Both decision making power and medicalisation remained significantly associated with type of delivery after controlling for other determinants. In the epidemiological sample, the association between number of antenatal visits (an indicator of medicalisation) and birth outcome also remained significant after controlling for other determinants (data not shown).

\section{Induction of birth}

Patterns for the induction of birth also highlight how medicalisation is negotiated. Older experienced women argued that induction often helped in acquiring a caesarean section, since increased pain from oxytocin and failed induction provided "hard" proof that labour would not succeed. Conversely, obstetricians believed that induction helped prevent caesarean sections. Among vaginal births only, a greater proportion of women with higher education (a good indicator of the power to negotiate) underwent induction (table 4). Among births by caesarean section only, however, maternal education was not associated with induction, whereas a greater proportion of women from families with lower incomes were induced. This confirms women's views that medical staff may induce a birth to prevent a caesarean section only when the woman is poor.

\section{Discussion}

Women's requests for caesarean sections in the absence of clear biological risks may seem irrational. However, traumatic birthing experiences often result from an antagonistic relationship with healthcare providers and a poor hospital environment-two aspects that are particularly acute for women who feel marginalised from society. What seems to underlie fear of vaginal delivery is not simply a lack of information on how to prepare for a vaginal birth but real issues relating to class based on differences in the quality of care provided.

Several studies exploring underlying influences with open ended methods found similar results. ${ }^{20-23}$ Indeed, many of the factors influencing maternal behaviours, such as fear of pain, are meaningful precisely because they are understood to differ by socioeconomic status and to be embedded in discriminating practices. In Brazil's plural healthcare system, there are alternative routes for women with marginal

Table 3 Logistic regression for type of birth in ethnographic sample of 80 women in Pelotas, 1993. Values are odds ratios (95\% confidence intervals) unless stated otherwise

\begin{tabular}{|c|c|c|c|c|}
\hline \multirow[b]{2}{*}{ Characteristic* } & \multicolumn{4}{|c|}{ Adjusted level } \\
\hline & Crude & 1 & $1-2$ & 1,2 , and 4 \\
\hline \multicolumn{5}{|l|}{ Level 1} \\
\hline Maternal schooling & $1.22(1.05$ to $1.42 ; P=0.01)$ & 1.19 (1.00 to $1.42 ; P=0.05)$ & 1.11 (0.9 to $1.3 ; P=0.25)$ & 1.00 (0.9 to $1.3 ; P=0.6)$ \\
\hline Family income $(\mathrm{n}=77)$ & 1.29 (1.05 to $1.60 ; P=0.02)$ & 1.16 (0.92 to $1.50 ; P=0.22)$ & $\dagger$ & $\dagger$ \\
\hline \multicolumn{5}{|l|}{ Level 2} \\
\hline Maternal power & 2.40 (1.43 to $4.0 ; P=0.008)$ & 2.20 (1.27 to $3.80 ; P=0.005$ ) & 2.10 (1.3 to $3.6 ; P=0.005)$ & 2.0 (1.1 to $3.5 ; P=0.02$ ) \\
\hline \multicolumn{5}{|l|}{ Level 3} \\
\hline Gestational risk & 0.90 (0.7 to $1.12 ; P=0.36$ ) & 1.0 (0.8 to $1.3 ; P=0.9)$ & $\dagger$ & $\dagger$ \\
\hline Primiparous & 2.50 (0.9 to $6.9 ; P=0.08)$ & 1.7 (0.6 to $5.1 ; P=0.3$ ) & $\dagger$ & $\dagger$ \\
\hline \multicolumn{5}{|l|}{ Level 4} \\
\hline Maternal medicalisation & 2.81 (1.51 to $5.22 ; \mathrm{P}=0.001$ ) & 2.62 (1.40 to $5.00 ; P=0.003)$ & 2.20 (1.17 to 4.22; $\mathrm{P}=0.01)$ & 2.00 (1.00 to $4.00 ; P=0.05)$ \\
\hline No of antenatal consultations & $1.29(1.06$ to $1.57 ; \mathrm{P}=0.01)$ & 1.28 (1.04 to $1.57 ; \mathrm{P}=0.02)$ & 1.28 (1.04 to $1.57 ; \mathrm{P}=0.02)$ & $1.22(1.0$ to $1.50 ; P=0.07)$ \\
\hline
\end{tabular}

tVariable excluded from model because significance level $>0.2$ at first level of adjustment. 
purchasing power to acquire a caesarean section other than by direct payment. After controlling for income and education, women's power to acquire a medicalised birth continued to have an effect on birth outcome.

In Brazil, one public health response has been to provide more education on the birth process, including risks associated with caesarean sections. This approach does not address the reasons for women's preferences nor that biological, institutional, and social variables are interdependent, as suggested by the holistic methods we used. Other studies have shown how health risks associated with birth progress are widely variable and sensitive to both the birthing environment and the nature of the doctor-patient relationship, making it difficult to standardise biological variables for "normal" births. ${ }^{14} 182425$

It is questionable whether a clinical trial comparing deliveries by elective caesarean section with vaginal delivery would help weigh the risks of each birth type. ${ }^{26}$ Results from such a trial would have limited applicability because variables associated with actual hospital environments and sociobiological judgments made by physicians would not be taken into account. Indeed, research should explore the medical culture, including both in-depth ethnography of the obstetric subspecialty and observations of interactions between physicians and patients.

If poor quality care, stimulated by socioeconomic inequalities, is behind many women's preferences for a caesarean section, then arguments supporting interventionist birthing "for all" on the basis of equal access to health care must be reviewed. Debates about the reduction of unnecessary medicalised procedures should include, in addition to biological risks, questions of economic inequality, quality of care, and

\section{What is already known on this topic}

Women's preferences for caesarean sections are understood to result from lack of knowledge and psychological aptitude to handle vaginal delivery and its consequences

Efforts to reduce the demand for caesarean sections have focused on providing consumers with correct information on the relative risks associated with vaginal and operative deliveries

\section{What this study adds}

In Brazil, many women prefer caesarean sections because they consider it good quality care

Rich women are more likely to have caesarean sections, supporting the notion that medical intervention represents superior care

Poor women may implement a series of medicalised practices that justifies the need for greater medical intervention during birth

Interventions for reducing caesarean sections by educating physicians and patients about risk factors associated with birthing procedures are not sufficient
Table 4 Percentages (numbers) of women induced according to type of birth in epidemiological sample of 5304 women in Pelotas, 1993

\begin{tabular}{|c|c|c|c|c|c|c|}
\hline & \multicolumn{2}{|c|}{ Vaginal deliveries } & \multirow[b]{2}{*}{ P value* } & \multicolumn{2}{|c|}{ Caesarean sections } & \multirow[b]{2}{*}{ P value* } \\
\hline & Induced & Not induced & & Induced & Not induced & \\
\hline \multicolumn{7}{|c|}{ Family income (minimum salaries) $\dagger$} \\
\hline $0-3$ & $65.8(918)$ & $66.2(1461)$ & 0.8 & $54.3(140)$ & $47.5(631)$ & 0.02 \\
\hline $3.1-6$ & $23.1(322)$ & $22.2(490)$ & & $26.7(69)$ & $25.3(336)$ & \\
\hline$>6$ & $11.1(155)$ & $11.6(257)$ & & $19.0(49)$ & $27.2(362)$ & \\
\hline \multicolumn{7}{|c|}{ Maternal schooling (years) } \\
\hline $0-4$ & $26.4(379)$ & $34.6(779)$ & 0 & $24.4(64)$ & $28.0(270)$ & 0.24 \\
\hline $5-8$ & $50.0(715)$ & $47.1(1061)$ & & $40.0(104)$ & $58.7(568)$ & \\
\hline$\geqslant 9$ & $23.7(339)$ & $18.3(411)$ & & $35.9(94)$ & $13.4(130)$ & \\
\hline \multicolumn{7}{|c|}{ No of antenatal visits } \\
\hline$\underline{0-4}$ & $18.2(260)$ & $23.4(526)$ & 0.001 & $10.3(27)$ & $10.0(130)$ & 0.9 \\
\hline $5-9$ & $58.3(833)$ & $54.4(1222)$ & & $49.2(129)$ & $49.3(668)$ & \\
\hline $10-20$ & $23.5(335)$ & $22.2(499)$ & & $40.5(106)$ & $41.1(557)$ & \\
\hline \multicolumn{7}{|c|}{ Gestational risk } \\
\hline Low (0-2) & $24.0(341)$ & $23.6(531)$ & 0.76 & $29.4(77)$ & 31.1 (423) & 0.01 \\
\hline Medium (3-7) & 64.1 (918) & $63.4(1427)$ & & $64.9(170)$ & $57.4(779)$ & \\
\hline High $(\geqslant 8)$ & $12.1(174)$ & $13.0(292)$ & & $5.7(15)$ & $11.5(156)$ & \\
\hline
\end{tabular}

${ }^{*} \chi^{2}$ test.

†One minimum salary $=\$ 100(£ 70)$.

the social determinants of caesarean section rates. What initially seems to be a democratic or "liberal" stance in awarding all the same access to healthcare technology could in actuality be a conservative and medically radical solution to the social inequalities that have led to an increase in caesarean section rates. Additional research is needed in settings where the economically based distribution of caesarean sections is not as discrepant as in Brazil. Even modest inequalities in healthcare provision might create a market for unnecessary interventions among women who feel marginalised from access to medical technology.

Contributors: DPB developed the core study hypothesis, was the principal investigator of the ethnographic study, carried out ethnographic fieldwork, conducted epidemiological and ethnographic data analysis, and wrote the paper; he will act as guarantor for the paper. CGV designed and executed the epidemiological study, discussed core ideas, conducted multivariate quantitative data analysis, and helped write the paper. FCB designed and executed the epidemiological study and discussed core ideas for the paper. All authors reviewed and approved the final version of the paper.

Funding: Funding for this study was provided by the European Community, the Fulbright Foundation (for DPB), and the Programa de Apoio a Núcleos de Excelência of the Brazilian government.

Competing interests: None declared.

1 Belizan J, Althabe F, Barros F, Alezander S. Rates and implications of caesarean sections in Latin America: ecological study. BMJ 1999;319:1397 402.

2 Barros F, Victora C, Morris S. Caesarean sections in Brazil. Lance 1996;347:839.

3 World Health Organization. Appropriate technology for birth. Lancet 1985;2:436-7.

4 Ash A, Okah D. What is the right number of caesarean sections? Lancet 1997;349:1557.

5 Al-Mufti R, McCarthy A, Fisk N. Obstetricians' personal choice and mode of delivery. Lancet 1996;347:544.

6 Geary M, Wilshin J, Persaud M, Hindmarch P, Rodeck C. Do doctors have an increased rate of caesarean section? Lancet 1998;351:1117.

7 Murray S, Pradenas F. Health sector reform and rise of caesarean birth in Chile. Lancet 1997;349:64.

8 Haines A. Health care in Brazil. BMJ 1993;306:503-6.

9 De Mello e Souza C. C-sections as ideal births: The cultural construction of beneficience and patients' rights in Brazil. Cambridge Q Healthcare Ethics 1994;3:358-66.

10 Lilford R, Van Coerverden deGroot H, Moore P, Gingham P. The relative risks of caesarean section (intrapartum and elective) and vaginal delivery: a detailed analysis to exclude the effects of medical disorders and other acute preexisting physiological disturbances. $\mathrm{Br} J$ Obstet Gynaecol 1990;97:883-92. 
11 Hemminki E, Merilainen J. Long-term effects of cesarean sections: ectopic pregnancies and placental problems. Am J Obstet Gynaecol 1996;174:1569-74

12 Thurmond A, Harvey W, Smith S. Cesarean section scar as a cause of abnormal vaginal bleeding: diagnosis by sonohysterography. J Ultrasound Med 1999;18:13-6, 17-8.

13 Editorial. What is the right number of caesarean sections? Lancet 1997;349(March 22):815.

14 Peterson-Brown S. Should doctors perform an elective caesarean section on request? $B M J 1998 ; 317: 462-3$

15 Barros F, Victora C, Vaughan J, Capellari M. Perinatal risk in third world cities. World Health Forum 1985;6:322-4.

16 Cosminsky S. Childbirth and change: a Guatemalan study. In: MacCormack CP, ed. Ethnography of fertility and birth. London: Academic Press, 1982:205-29.

17 MacCormack C, ed. Ethnography of fertility and birth. London: Academic Press, 1982.

18 Kaufert P, O'Neil J. Analysis of a dialogue on risks in childbirth: clinicians, epidemiologists, and Inuit women. In: S Lindenbaum ML, ed. Knowledge, power and practice: the anthropology of medicine and everyday life. Berkeley: University of California Press, 1993:32-54.
19 Victora C, Barros F, Vaughan J. Epidemiologia de la desigualdad [Epidemiology of inequality]. Washington DC: Pan-American Health Organization, 1992.

20 Davis-Floyd R. The technocratic body: American childbirth as cultural expression. Soc Sci Med 1993;38:1125-40.

21 LoCicero A. Explaining excessive rate of cesareans and other childbirth interventions: contributions from contemporary theories of gender and psychosocial development. Soc Sci Med 1993;37:1261-9.

22 McClain C. Patient decision making: the case of delivery method after a previous cesarean section. Cult Med Psychiatry 1987;11:495-508.

23 Sargent C, Stark N. Surgical birth: interpretations of cesarean delivery among private hospital patients and nursing staff. Soc Sci Med 1987;25:1269-76.

24 Klaus M, Kennell J, Robertson S, Rosa R. Effects of social support during parturition on maternal and infant morbidity. BMJ 1986;293:585-7.

25 Chalmers I, Enkin M, Keirse M. Effective care in pregnancy and childbirth, vol 2. Oxford: Oxford University Press, 1989.

26 Bewley S. Obstetricians' views on caesarean section versus vaginal birth. Lancet 1996;347:1189.

(Accepted 7 November 2001) 